\title{
Porcine bladder urothelial, myofibroblast, and detrusor muscle cells: characterization and ATP release
}

\section{Ying Cheng ${ }^{1}$, Kylie J. Mansfield ${ }^{2}$, Shaun L. Sandow ${ }^{3}$, Prajni Sadananda $^{3}$, Elizabeth Burcher ${ }^{3}$ and Kate H. Moore ${ }^{1}$}

1 Detrusor Muscle Laboratory, St George Hospital, University of New South Wales, Kogarah, NSW, Australia

${ }^{2}$ Graduate School of Medicine, University of Wollongong, Wollongong, NSW, Australia

${ }^{3}$ Department of Pharmacology, School of Medical Sciences, University of New South Wales, Sydney, NSW, Australia

Edited by:

Bimal Malhotra, Pfizer, USA

Reviewed by:

Peter Ochodnicky, Academic Medical Center Amsterdam, Netherlands

Robert S. Moreland, Drexel University College of Medicine, USA

Robert James Theobald, A. T. Still

University of Health

Sciences-Kirksville College of

Osteopathic Medicine, USA

${ }^{*}$ Correspondence:

Kylie J. Mansfield, Graduate School of Medicine, University of Wollongong, Northfields Avenue, Wollongong,

NSW 2522, Australia.

e-mail:kylie_mansfield@uow.edu.au
ATP is released from the bladder mucosa in response to stretch, but the cell types responsible are unclear. Our aim was to isolate and characterize individual populations of urothelial, myofibroblast, and detrusor muscle cells in culture, and to examine agonist-stimulated ATP release. Using female pig bladders, urothelial cells were isolated from bladder mucosa following trypsin-digestion of the luminal surface. The underlying myofibroblast layer was dissected, minced, digested, and cultured until confluent (10-14 days). A similar protocol was used for muscle cells. Cultures were used for immunocytochemical staining and/or ATP release investigations. In urothelial cultures, immunoreactivity was present for the cytokeratin marker AE1/AE3 but not the contractile protein $\alpha$-smooth muscle actin ( $\alpha$-SMA) or the cytoskeletal filament vimentin. Neither myofibroblast nor muscle cell cultures stained for AE1/AE3. Myofibroblast cultures partially stained for $\alpha$-SMA, whereas muscle cultures were $100 \%$ stained. Both myofibroblast and muscle stained for vimentin, however, they were morphologically distinct. Ultrastructural studies verified that the suburothelial layer of pig bladder contained abundant myofibroblasts, characterized by high densities of rough endoplasmic reticulum. Baseline ATP release was higher in urothelial and myofibroblast cultures, compared with muscle. ATP release was significantly stimulated by stretch in all three cell populations. Only urothelial cells released ATP in response to acid, and only muscle cells were stimulated by capsaicin. Tachykinins had no effect on ATP release. In conclusion, we have established a method for culture of three cell populations from porcine bladder, a well-known human bladder model, and shown that these are distinct morphologically, immunologically, and pharmacologically.

Keywords: ATP, porcine, bladder, urothelium, myofibroblast, detrusor, ultrastructure

\section{INTRODUCTION}

Studies on the etiology of the overactive bladder have traditionally focused on the detrusor muscle. Recently, the bladder mucosa has received greater attention as the source of aberrant afferent signaling. Lining the bladder is a transitional epithelium (the urothelium), which has key roles in both sensory and motor function (Birder, 2006). Underneath the urothelium, within the lamina propria, is a layer of suburothelial interstitial cells considered to be myofibroblasts (Sadananda et al., 2008). Myofibroblasts are spindle shaped branching cells, which form gap junctions with neighboring myofibroblasts, with connective tissue elements in the lamina propria (Fry et al., 2007) as well as with suburothelial nerves (Wu et al., 2004; Sui et al., 2006). These cells appear to form a network (Davidson and McCloskey, 2005) and have been postulated to have a pacemaker function, similar to interstitial cells of Cajal (ICC) in the gut (McCloskey, 2010). Suburothelial myofibroblasts contain nitric oxide synthase (Gillespie et al., 2006) and are a focus of current research since they may act as a link in the signal transduction process between urothelial stretch and afferent excitation of adjacent suburothelial nerves (Wu et al., 2004).
In response to stretch and other stimuli, the urothelium can release several mediators, including the signaling molecule ATP, from animal (Ferguson et al., 1997; Munoz et al., 2010) and human bladder (Kumar et al., 2004). ATP is essential for initiation of the normal micturition reflex (Cockayne et al., 2000). ATP can be released from parasympathetic nerves but is also an important and ubiquitous signaling molecule from non-neuronal sources (Burnstock, 2007) and acts on several different G-protein-coupled P2Y and ionotropic P2X receptors (Burnstock, 2007). For example, ATP stimulates purinergic $\mathrm{P}_{2} \mathrm{X}_{3}$ receptors to increase afferent nerve activity (Burnstock, 2007), thus eliciting sensations of bladder fullness (via low threshold nerves) and pain (via high threshold nerves; Ferguson et al., 1997). In women with bladder dysfunction stretch induced ATP release is increased (Kumar et al., 2007, 2010; Cheng et al., 2010).

ATP release studies have utilized a number of different models ranging from whole bladders through to mucosal strips and urothelial cell cultures. Mucosal strips contain a number of cell types including urothelial cells and myofibroblasts. ATP release studies from bladder cells in culture have been confined to 
urothelial cells. Exposure of urothelial cells to hypotonic solution, which is hypothesized to mimic stretch, can elicit ATP release in cultures (Birder et al., 2002, 2003). In addition to stretch, some studies have indicated that urothelial cells release ATP in response to TRPV1 agonists, capsaicin (Charrua et al., 2009; Sadananda et al., 2009b), and acid (Sadananda et al., 2009a,b). It remains unclear whether other mucosal cell populations can also release ATP. Myofibroblasts have been shown to exhibit spontaneous depolarizations as well as generate currents in response to ATP (via P2Y receptors; Wu et al., 2004; Sui et al., 2006). However, the ability of myofibroblasts to release ATP has not been investigated.

Tachykinin peptides (neurokinin A and substance P) are present in human bladder afferent nerves (Smet et al., 1997). Tachykinin receptors have been demonstrated in bladder mucosa and detrusor (Burcher et al., 2000; Templeman et al., 2003; Sellers et al., 2006). In the pig mucosal strips, our group has found that activation of tachykinin NK2 receptors by neurokinin A causes contraction (Sadananda et al., 2008). However the role of tachykinins in ATP release has not been investigated.

Both urothelial cells and detrusor muscle cells are relatively straightforward to isolate and propagate in culture (Birder et al., 2003; Sun and Chai, 2002). AE1/AE3 is a marker for urothelial cells known to react against an antigenic determinant present on the majority of the subfamily A and B cytokeratins (Eichner et al., 1984; Sun et al., 1984), and has previously been employed in studies of the urothelium (Trifillis et al., 1995; Southgate et al., 1999). Smooth muscle actin ( $\alpha$-SMA) is a contractile protein present in both smooth muscle (Roholl et al., 1990) and myofibroblasts (Drake et al., 2006; Sadananda et al., 2008; Iwanaga et al., 2010; McCloskey, 2010). Desmin is an intermediate contractile filament that is a muscle specific protein (Gallanti et al., 1992; Paulin and Li, 2004). Another cytoskeletal contractile filament, vimentin, was also used as a marker for smooth muscle (Wood et al., 2004) and is commonly used to stain myofibroblasts and fibroblasts (Wu et al., 2004; Gillespie et al., 2006; Sui et al., 2006; Johnston et al., 2010; McCloskey, 2010). In pig bladder sections, the suburothelial layer of myofibroblasts/interstitial cells is immunoreactive for $\alpha$-SMA as well as for vimentin (Sadananda et al., 2008).

Smooth muscle cells can undergo phenotypic changes in culture, which affects their expression of a number of markers including $\alpha$-SMA and desmin (Nair et al., 2011) although detrusor smooth muscle cells were seen to retain their contractility in culture (Wood et al., 2004). A method for reliable culture of bladder myofibroblasts has not been reported. The initial aim of this study was to establish a consistent method to isolate a population of suburothelial myofibroblasts from pig bladder, separate from urothelial and detrusor muscle cells. We then examined the ability of each cell population isolated to release ATP in response to a number of stimuli including stretch, acid, capsaicin, and tachykinins. Parallel ultrastructural studies of the mucosa were also conducted to visualize the individual cell types present.

\section{MATERIALS AND METHODS \\ ISOLATION OF INDIVIDUAL CELL POPULATIONS}

Female pig bladders were obtained from an abattoir on ice within $2 \mathrm{~h}$ of sacrifice and dissected immediately into mucosa and detrusor, prior to establishing individual urothelial, myofibroblast, and detrusor muscle cultures. Not every bladder yielded material sufficient for culture of all three cell types.

Urothelial cell cultures were obtained by digestion from the luminal surface with $0.25 \%$ trypsin-EDTA for $10 \mathrm{~min}$ at $37^{\circ} \mathrm{C}$. After digestion, the detached epithelial cells were scraped off the luminal surface using a cell scraper and the trypsin inactivated with an equal volume of RPMI 1640 (GIBCO, Australia) supplemented with $10 \%$ fetal bovine serum (FBS). Cells were separated by centrifugation at $750 \mathrm{~g}$ for $5 \mathrm{~min}$, then resuspended in RPMI supplemented with $10 \%$ FBS, antibiotic/antimyotic, epithelial cell growth factor $(25 \mathrm{ng} / \mathrm{ml})$. Cells were plated in 48 -well plates at approximately $10^{6}$ cell per well and incubated at $37^{\circ} \mathrm{C}$ in $5 \% \mathrm{CO}_{2}$ until confluent.

Myofibroblast cell cultures were established from mucosa that had been dissected away from the detrusor muscle. The urothelial cells were removed from the luminal surface by gently scraping with a scalpel blade. Loose connective tissue, blood vessels, and smooth muscle strands were then removed from the lamina propria using a dissecting microscope. The remaining transparent suburothelial layer $(2 \mathrm{~cm} \times 0.5 \mathrm{~cm})$ was minced and treated with $0.25 \%$ trypsin-EDTA with $0.15 \%$ collagenase type II for $30 \mathrm{~min}$ at $37^{\circ} \mathrm{C}$. The digested tissue was triturated with a transfer pipette 10 times, and undigested tissue pieces were removed with a cell strainer (100 $\mu \mathrm{m}$ pore size). Trypsin was inactivated with an equal volume of RPMI 1640 with 10\% FBS. Cells were pelleted at $1600 \mathrm{~g}$ for $10 \mathrm{~min}$, then resuspended in RPMI and plated as described above for urothelial cells.

Detrusor muscle was minced and then digested with $0.25 \%$ trypsin-EDTA and $0.15 \%$ collagenase at $37^{\circ} \mathrm{C}$. After $30 \mathrm{~min}$ the digested tissue was triturated and undigested tissue removed using a cell strainer (100 $\mu \mathrm{m}$ pore size). Trypsin was inactivated using an equal volume of RPMI supplemented with 10\% FBS. Muscle cells were isolated at $1600 \mathrm{~g}$ for $10 \mathrm{~min}$, resuspended and plated as described above.

\section{FLUORESCENT IMMUNOCYTOCHEMICAL CHARACTERIZATION OF ISOLATED CELLS}

Once the individual urothelial, myofibroblasts, and muscle cell cultures became confluent (approximately 10-14 days), culture media was removed and cells washed with $0.01 \mathrm{M}$ phosphate buffered saline (PBS) for $10 \mathrm{~min}$. Cells were fixed with ethanol (100\%) for $15 \mathrm{~min}$ at room temperature then washed once with PBS. Cells were incubated overnight at $4^{\circ} \mathrm{C}$ with the primary antibody $(1: 100$ dilution in RPMI culture media supplemented with 10\% FBS). Cells were washed with PBS ( $3 \mathrm{~min} \times 5 \mathrm{~min}$ ), and incubated for $1 \mathrm{~h}$ at room temperature with fluorescein isothiocyanate (FITC)conjugated anti-mouse IgG antibody, diluted in RPMI culture media supplemented with $10 \%$ FBS. Cells were counterstained with nuclear stain 4',6-diamidino-2-phenylindole (DAPI) diluted in PBS for $5 \mathrm{~min}$ at room temperature, then washed with PBS $(3 \times 5 \mathrm{~min})$.

Stained cells were viewed with an inverted microscope (Leica DM IRB), using filters (Em/Ex) 535/475 nm for FITC and $480 / 440 \mathrm{~nm}$ for DAPI. No immunoreactivity was observed in control slides where primary antibody was excluded. Immunoreactivity was assessed in relation to the number of cells present in the field. This was quantified in three fields and three replicates 
for each cell population in each pig. The results were expressed as: 0 , no immunoreactivity detected; + , positive immunoreactivity in a minority of cells; ++ , positive immunoreactivity in all or most cells.

\section{TISSUE PREPARATION FOR ELECTRON MICROSCOPY}

Tissue preparation and analysis for conventional electron microscopy was as previously described (Sandow et al., 2002). In brief, small segments of bladder were immersion fixed in fresh $3 \%$ glutaraldehyde and $2 \%$ paraformaldehyde in $0.1 \mathrm{M}$ cacodylate buffer, $15 \mathrm{mM}$ betaine, $\mathrm{pH} 7.4$ for $20 \mathrm{~min}$, and stained/postfixed in $4 \%$ osmium in the same buffer, before block staining in saturated uranyl acetate. Tissue was then embedded in Araldite 502, sectioned with a diamond knife, stained in lead citrate, and imaged on a Philips 7100 transmission electron microscope, using a digital camera at 16 megapixel resolution.

\section{STIMULATION OF ATP RELEASE}

Confluent cell cultures $\left(10^{6}\right.$ cells per well, after approximately 10-14 days) were equilibrated with sterile gassed $\left(95 \% \mathrm{O}_{2}, 5 \%\right.$ $\mathrm{CO}_{2}$ ) Krebs-Henseleit solution (composition in mM: $\mathrm{NaCl} 118$, $\mathrm{KCl} 4.7, \mathrm{NaHCO}_{3} 25, \mathrm{KH}_{2} \mathrm{PO}_{4} 1.2, \mathrm{MgSO}_{4} 1.2, \mathrm{CaCl}_{2} 2.5$, and D-glucose 11.7) for $1 \mathrm{~h}$.

After the equilibration, cells were exposed to $200 \mu \mathrm{l}$ of normal Krebs-Henseleit (control), hypotonic Krebs-Henseleit (1:2 dilution of Krebs-Henseleit in distilled water), acidic Krebs-Henseleit ( $\mathrm{pH}$ adjusted to 6.4 with $\mathrm{HCl}$ ), or agonist. Where appropriate, control cells were treated with vehicle (see Materials and Methods). Cells were treated for $10 \mathrm{~min}$ before the supernatant $(200 \mu \mathrm{l})$ was collected and used for ATP determinations. In preliminary studies, 10 min was established as the optimum incubation time.

ATP concentration in the supernatant was measured as described previously (Sadananda et al., 2009a). An equal volume of the treatment supernatant or ATP standard solutions was mixed with the bio-luminescence assay mix and the luminescence generated was measured immediately with a luminometer (GloMax 20/20). A standard curve was created by plotting luminescence against the standard ATP concentrations $\left(10^{-6}\right.$ to $\left.10^{-10} \mathrm{M}\right)$. The ATP concentration in the cell supernatant of either controls or treated cells was calculated relative to the standard curve. Acid at $\mathrm{pH} 6.4$ and vehicle (DMSO and peptide solution), at working concentrations, did not affect luminescence readings (data not shown).

Table 1 | Summary of fluorescent immunocytochemical staining of urothelial, myofibroblast, and muscle cell cultures.

\begin{tabular}{lccc}
\hline Antibody & Urothelial & Myofibroblast & Muscle \\
\hline AE1/AE3 & $++(n=6)$ & $0 /+(n=6)$ & $0(n=6)$ \\
$\alpha$-smooth muscle actin & $0(n=6)$ & $+(n=6)$ & $++(n=6)$ \\
Vimentin & $0(n=6)$ & $++(n=6)$ & $++(n=6)$ \\
Desmin & $0(n=4)$ & $0(n=4)$ & $+(n=4)$ \\
\hline
\end{tabular}

0, no immunoreactivity detected; + , positive immunoreactivity in a minority of cells; ++ , positive immunoreactivity in all or most cells.
Treatments were carried out in quadruplicate and the mean ATP concentration (in nanomolar) per treatment determined. Stretch and agonist-stimulated ATP release was not normally distributed and is presented as median (with interquartile range). Comparisons between control and treated cells or between vehicle and treated cells were carried out using Wilcoxon matched pairs test or Friedman's one way ANOVA, with Dunn's post hoc test as appropriate. Data are also expressed as percentage of basal release (median). The $n$ value was taken as the number of pigs.

\section{MATERIALS}

Unless otherwise specified, all cell culture reagents were purchased from Invitrogen (Mount Waverley, Australia). All primary antibodies were from DakoCytomation (Campbellfield, Australia). FITC-conjugated anti-mouse IgG was from Abcam (Waterloo, Australia). Bio-luminescence ATP Assay kit, DAPI, and capsaicin was from Sigma-Aldrich (Sydney, Australia). Capsaicin was dissolved in DMSO. NKA and SP were purchased from Auspep (Tullamarine, Australia) and were dissolved in peptide solution $(0.01 \mathrm{M}$ acetic acid with $1 \%$ mercaptoethanol). Stock concentrations of capsaicin and tachykinins (all $10 \mathrm{mM}$ ) were then diluted in Krebs. All other reagents were of high analytical grade.

\section{RESULTS}

\section{IMMUNOCYTOCHEMICAL CHARACTERIZATION OF CULTURED} UROTHELIAL, MYOFIBROBLASTS, AND MUSCLE CELLS

Individual populations of urothelial, myofibroblasts, and detrusor muscle cells were isolated. Urothelial cells appeared rounded with a smooth cell surface and demonstrated immunoreactivity for the cytokeratin marker AE1/AE3 (Figure 1A), but not for the contractile protein $\alpha$-SMA (Figure 1B) or the cytoskeletal filament vimentin (Figure 1C; Table 1).

Myofibroblast cultures displayed minimal immunoreactivity for AE1/AE3 (Figure 1D; Table 1). Occasional cells in the myofibroblast cultures stained positively for AE1/AE3 and showed urothelial cell type morphology. A minority of cells in the myofibroblast cultures were positive to $\alpha$-SMA (Figure 1E; Table 1). However, all cells in the myofibroblast cultures showed strong immunoreactivity for vimentin (Figure 1F).

Muscle cell cultures showed no immunoreactivity for AE1/AE3 (Figure 1G), but showed strong (100\%) immunoreactivity for $\alpha$-SMA (Figure 1H) and vimentin (Figure 1I). Immunoreactivity to $\alpha$-SMA was present in all muscle cells in culture, but only partially in myofibroblast cells (Table 1). Myofibroblast and muscle cell cultures also differed morphologically. Myofibroblasts tended to be spreading with numerous long processes (Figure 2A); at confluence, these long cell processes gave the cultures a complex overlapping appearance (Figure 1F). In contrast, muscle cells appeared as elongated bipolar cells (Figure 2B). A minority of muscle cells was weakly immunoreactive for desmin (Figure 2C), but urothelial and myofibroblast cultures were completely negative for desmin (Table 1).

\section{ULTRASTRUCTURAL OBSERVATIONS}

Transverse sections of pig bladder mucosa were examined ultrastructurally to clarify the observations in culture in comparison 


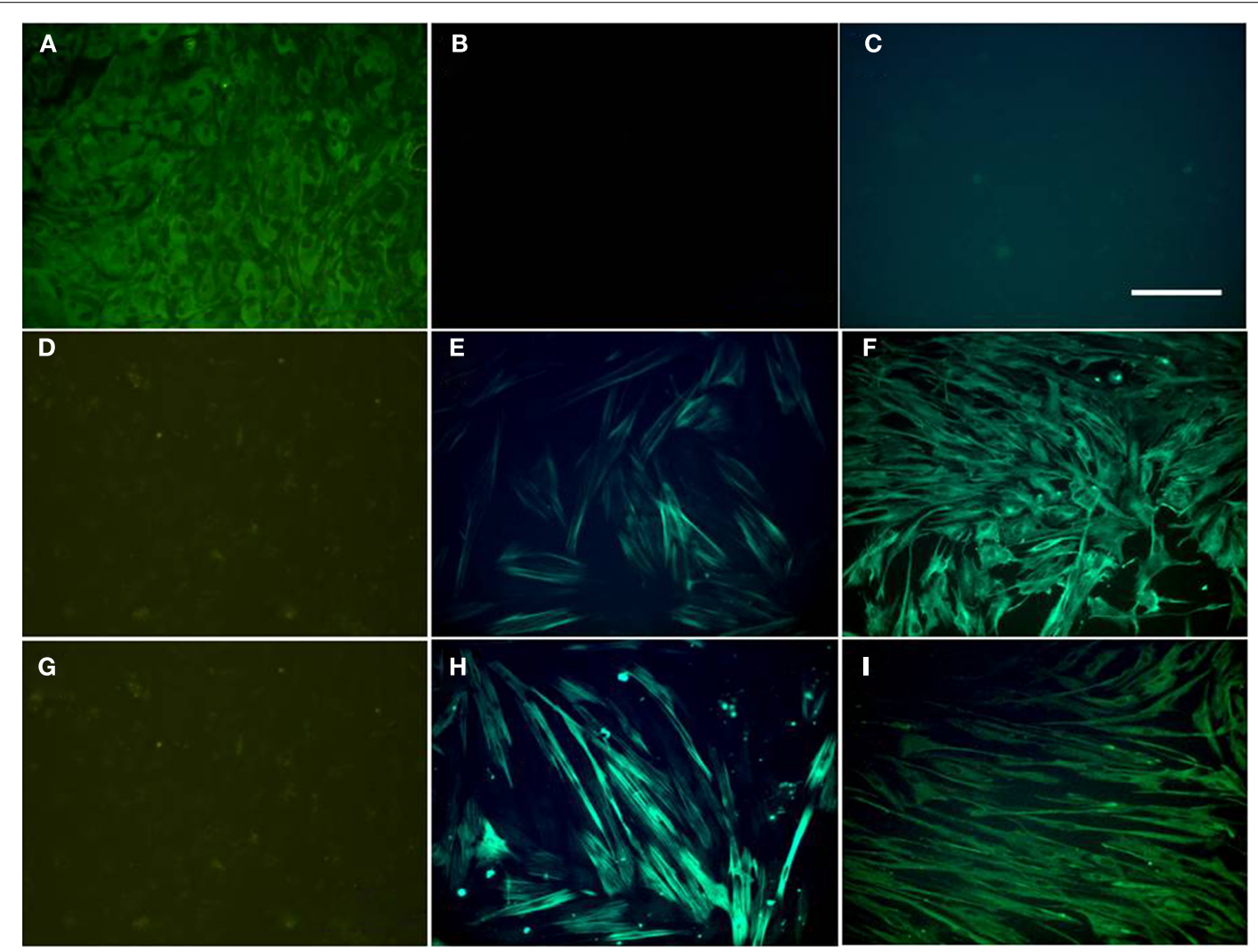

FIGURE 1 | Fluorescence immunocytochemistry of cultured urothelial (A-C), myofibroblast (D-F), and detrusor muscle (G-I) cells. Cultured cells were stained with the cytokeratin marker AE1/AE3 (A,D,G), the smooth muscle marker $\alpha$-SMA $(\mathbf{B}, \mathbf{E}, \mathbf{H})$, and vimentin $(\mathbf{C}, \mathbf{F}, \mathbf{I})$. All panels are shown at the same magnification. Bar $=200 \mu \mathrm{m}$.

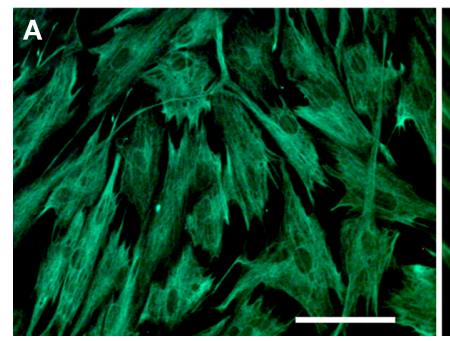

FIGURE 2 | High power fluorescence immunocytochemistry of cultured myofibroblast $(\mathbf{A})$ and detrusor muscle $(B, C)$ cells. Note the difference in morphology between myofibroblast (A) and muscle (B) cells, both stained with vimentin. In (C), muscle cells were double stained with desmin and DAPI. Note that only a minority of muscle cells was weakly immunopositive for desmin. Desmin did not stain urothelial and myofibroblast cultures (not shown). All panels are shown at the same magnification. $\operatorname{Bar}=100 \mu \mathrm{m}$. with those from intact tissue. Several layers of urothelial cells, with characteristic large nuclei, constituted an approximate $20 \mu \mathrm{m}$ depth of the porcine bladder wall (Figure 3A). Directly beneath the urothelium there was a dense network (approximately $20 \mu \mathrm{m}$ in width) of collagen fibers that contained thin, elongated myofibroblasts and small diameter blood vessels (Figure 3A); larger blood vessels were found deeper in the lamina propria (Figure 3A). Myofibroblasts were found scattered throughout the lamina propria with those located deeper appearing less numerous, shorter and thicker (with increased cell depth) than the suburothelial myofibroblasts. Myofibroblasts had abundant rough endoplasmic reticulum (Figures 3B,C). Occasional nerve bundles were present in the vicinity of myofibroblasts.

\section{ATP RELEASE FROM CULTURED UROTHELIAL, MYOFIBROBLAST, AND MUSCLE CELLS}

Basal ATP release from urothelial and myofibroblast cultures was similar [median (IQR) values 13.7 (7.9-20.9) and 12.2 (7.4-21.2) $\mathrm{nM}$, respectively; $n=16-18]$. Basal ATP release from detrusor muscle cultures [6.6 (3.0-11) nM; $n=9$ ], was significantly less 


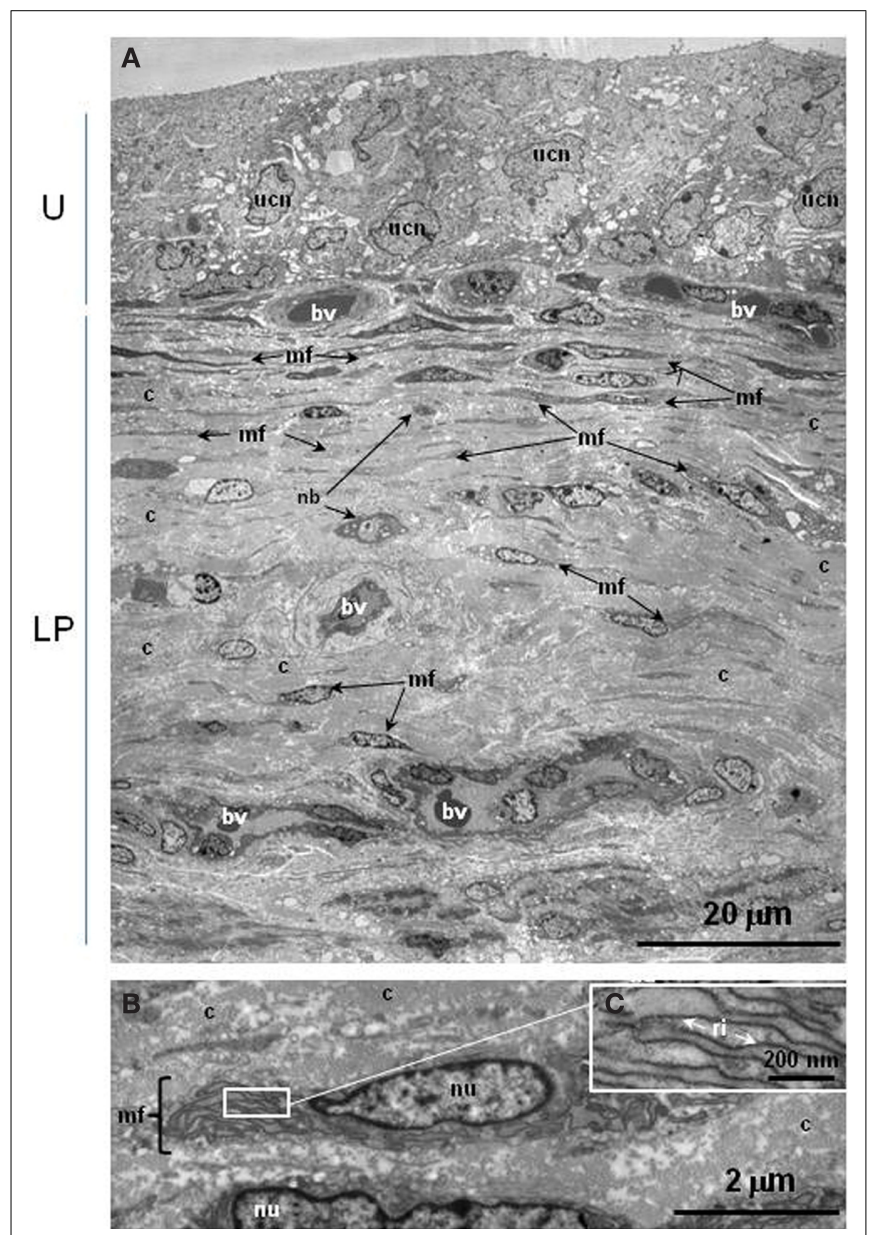

FIGURE 3 | Ultrastructure of pig urinary bladder mucosa. (A) Low power photomontage showing urothelium (top, U) with lamina propria (LP) underneath. Myofibroblasts are distributed extensively underneath the urothelium and are found diffusely throughout the entire lamina propria. (B) Higher power photomicrograph of myofibroblast with (C), inset, enlargement of rough endoplasmic reticulum. bv, blood vessel; c, collagen; $\mathrm{mf}$, myofibroblast; nb, nerve bundle; nu, nucleus of myofibroblast; ri, ribosomes; ucn, urothelial cell nucleus.

( $P<0.0001$, Kruskal-Wallis test $)$. The diluted vehicle solutions alone (DMSO and peptide solution) had no significant effect on ATP release from urothelial and myofibroblast cells $(n=16-$ 19, data not shown). However, the diluted peptide solution significantly increased ATP release from detrusor muscle cells [from median (IQR) $4.6(2.6-6.2)$ to $6.1(4.2-10.2) \mathrm{nM} ; n=20$; $P=0.0016]$.

Incubation in hypotonic Krebs-Henseleit solution triggered significant ATP release from urothelial, myofibroblast, and detrusor muscle cultures (Figures $\mathbf{4 A - C}$ ) compared to paired cultures treated with Krebs-Henseleit solution. This increased ATP release represented (median) 206\% for urothelial cells, 238\% for myofibroblasts, and $224 \%$ for smooth muscle cells, compared with basal (100\%). Acid at pH 6.4 elicited a small but significant increase in ATP release (to 121\% of basal) from urothelial cells (Figure 4D) but not from myofibroblast (Figure 4E) or muscle cultures (Figure 4F). Capsaicin ( $1 \mu \mathrm{M}$, in DMSO) was ineffective in urothelial (Figure 5A) or myofibroblast cultures (Figure 5B) but did significantly increase ATP release (to $121 \%$ of vehicle DMSO) from muscle cultures (Figure 5C). Neurokinin A and substance $\mathrm{P}$ ( $1 \mu \mathrm{M}$, in peptide solution) were unable to elicit ATP release from any of the three different cell cultures (Figures 5D-F).

\section{DISCUSSION}

Normal human bladder is not readily available in clinical practice, and thus we have used porcine bladders, which are a recognized model for the human bladder (Hashitani and Brading, 2003; Templeman et al., 2003; Kumar et al., 2004; Akino et al., 2008; Sadananda et al., 2008; Hernández et al., 2009). Here, we report a method for the primary culture of individual populations of myofibroblasts as well as urothelial and detrusor muscle cells from pig bladder, and we used these to quantify the release of ATP by various stimuli. A key question is whether the "myofibroblast cell cultures" were in fact myofibroblasts, rather than urothelial or muscle cells. We concluded that the three different culture types were quite distinct with respect to morphology, immunostaining, basal ATP release, and ATP released in response to stimuli, as discussed below.

In culture, urothelial cells have previously been characterized by their staining with cytokeratins (Sun et al., 2001; Birder et al., 2002; Sun and Chai, 2002), and we verified that our urothelial cultures showed the expected immunoreactivity to cytokeratins. Morphologically, the urothelial cells had a characteristic epithelial cobblestone-like appearance. In contrast, the branching processes of the myofibroblast cells gave these cultures a web-like appearance, similar to that described for myofibroblasts previously (Davidson and McCloskey, 2005). Thus, our putative myofibroblast cultures could be distinguished from the urothelial cultures not only by their morphology but also by the myofibroblasts' virtual absence of immunoreactivity for cytokeratins. Those few cells in the myofibroblast cultures that did stain for cytokeratins are likely to be urothelial cells.

In contrast to the urothelial cell cultures, the myofibroblast cultures showed strong and consistent immunoreactivity for vimentin, a marker commonly used for myofibroblasts/suburothelial cells (Wu et al., 2004; Gillespie et al., 2006; Sui et al., 2006; Johnston et al., 2010). However, vimentin also stains some other cell types such as our muscle cultures. Thus, vimentin immunoreactivity alone is ineffective as a marker to differentiate porcine myofibroblast from detrusor muscle cells. Nevertheless, the branching morphology of myofibroblast cultures was quite different from the narrow, unidirectional appearance of the smooth muscle cultures, which was obvious when comparing their appearance in cultures immunostained with vimentin. Previous authors have used $\alpha$-SMA as a marker for myofibroblasts in tissue sections (Drake et al., 2006; Sadananda et al., 2008; McCloskey, 2010) and cultured cells (Iwanaga et al., 2010). Although our porcine myofibroblast cultures demonstrated some immunoreactivity for $\alpha$-SMA, this marker showed stronger immunostaining in detrusor muscle cultures than in myofibroblast cultures. Based solely on the $\alpha$-SMA results, we cannot exclude the possibility that the myofibroblast cultures contained some smooth muscle cells. In addition, some cells in our muscle cultures, but not myofibroblast cultures, demonstrated positive immunoreactivity to desmin (Paulin and 

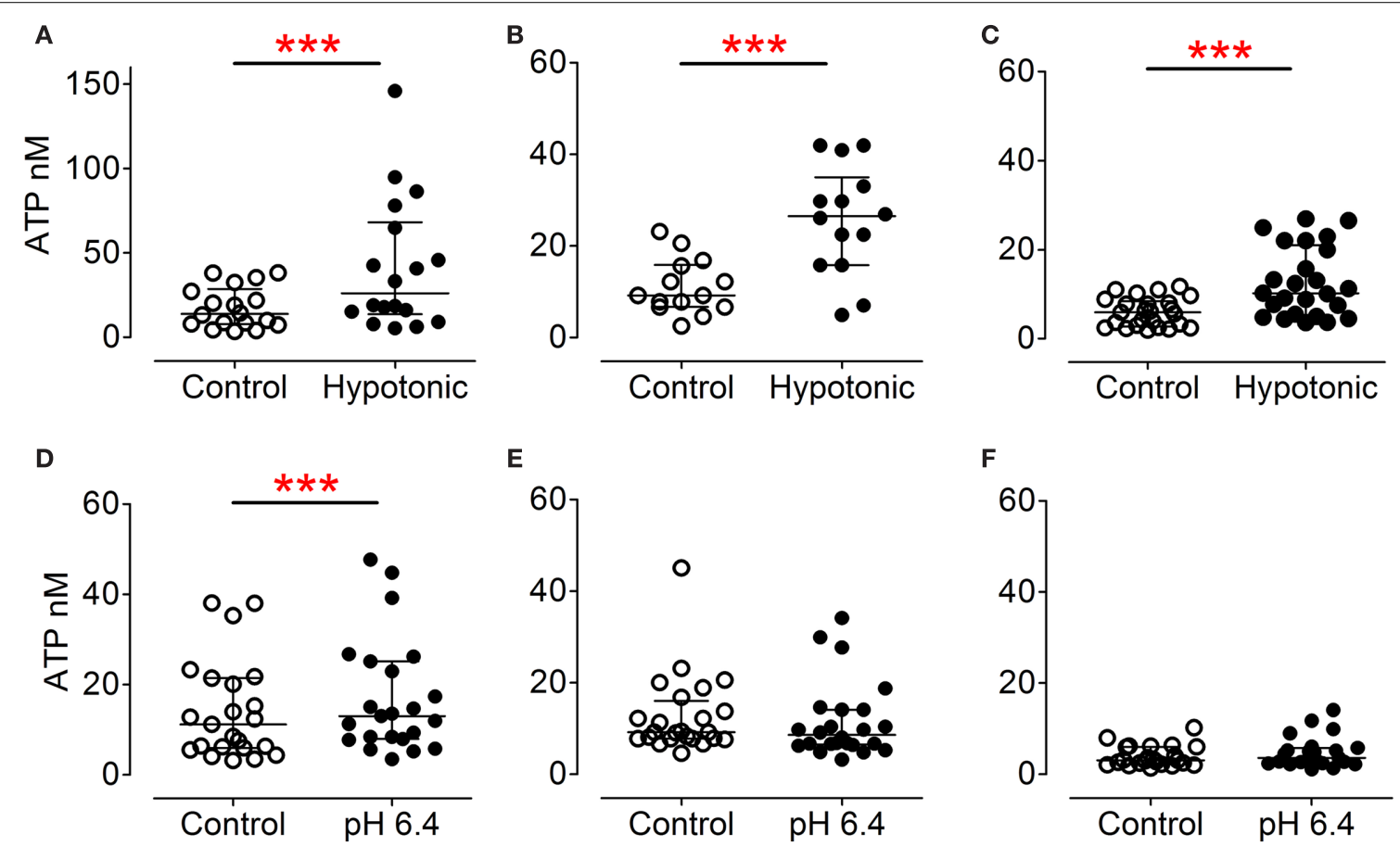

FIGURE 4 | ATP release from cultured urothelial (A,D), myofibroblast $(\mathbf{B}, \mathbf{E})$ and detrusor cells $(\mathbf{C}, \mathbf{F})$. Hypotonic Krebs-Henseleit solution (A-C) significantly stimulated ATP release from urothelial [(A) $P=0.0002, n=18$, Wilcoxon matched pairs test], myofibroblasts [(B), $P=0.001, n=14$, Wilcoxon] and detrusor [(C), $P<0.0001, n=25$,
Wilcoxon] cultures. Incubation in acidic Krebs-Henseleit solution ( $\mathrm{pH}$ 6.4) significantly induced ATP release from urothelial cells [(D), $P=0.0002, n=23$, Wilcoxon], but had no effect on myofibroblasts [(E), $P=0.42, n=24$, Wilcoxon] or smooth muscle cultures $[(\mathbf{F}), P=0.20, n=23$, Wilcoxon].
Li, 2004; Iwanaga et al., 2010). Not all cells in the muscle cultures were desmin-immunoreactive, although this is to be expected as expression of desmin is lost with culture (Nair et al., 2011).

As well as immunocytochemical differences, muscle and myofibroblast cultures were distinguished on the basis of their ability to release ATP. Myofibroblast cultures showed significantly higher basal ATP release when compared with muscle cultures. In fact, the pure detrusor muscle cultures displayed 50\% less basal release of ATP. This supports the original publication by Ferguson showing that the source of ATP release in the bladder was the mucosa not detrusor (Ferguson et al., 1997). In addition, the vehicle solution had no effect upon myofibroblast release of ATP, but this solution significantly increased release in the muscle. Furthermore, detrusor muscle but not myofibroblast cultures released ATP in response to capsaicin.

In addition to vimentin and $\alpha$-SMA, suburothelial interstitial cells in guinea-pig and human bladders are commonly identified using c-kit staining (Davidson and McCloskey, 2005; Johnston et al., 2010; McCloskey, 2010). The previous work of our group found that c-kit failed to demonstrate immunoreactivity in suburothelial myofibroblasts in pig bladder sections (Sadananda et al., 2008), possibly due to a lack of antibody specificity in the pig. Therefore, currently available antibodies for c-kit are not suitable for identification of interstitial cells in pigs. It is worthwhile to consider whether myofibroblasts in the bladder should be functionally different from the c-kit staining gastrointestinal ICC. The ICCs generate spontaneous potentials responsible for the rhythmic contraction of the gut, whereas the bladder is quiescent in the filling phase of the cycle (Hashitani and Brading, 2003). Our ultrastructural studies showed a dense layer of myofibroblasts underneath the urothelium and support the conclusion that our cells cultured from below the urothelium are likely to be myofibroblasts. Ultrastructurally, these elongated suburothelial cells were morphologically similar to the deep myofibroblasts of human detrusor (Rasmussen et al., 2009), in that they have prominent rough endoplasmic reticulum and elongated processes.

Hypotonic media, a commonly used stretch stimulus for urothelial cell culture studies (Birder et al., 2002, 2003), was able to stimulate ATP release from all three cell populations. Urothelial and myofibroblast cultures had much higher stretch-evoked ATP release compared with the muscle cultures. In porcine bladder, myofibroblasts are closely associated with peptide containing nerve terminals (Sandow et al., 2010), and the ATP released from myofibroblasts may therefore be involved with activation of sensory afferent nerves. It was notable that hypotonic media (stretch) was the only stimulus to elicit ATP release from myofibroblasts. Myofibroblasts are known to express ATP-sensitive P2Y receptors (Wu et al., 2004; Sui et al., 2006) and P2X 3 receptors (Liu et al., 2009) and could be a target for ATP released from the urothelium or elsewhere. They may also have a mechanosensory role in their own right. This role of ATP in sensory pathways is strengthened by our recent finding in overactive bladder patients, showing that the concentration of ATP released into voided urodynamic fluid correlates with the measures of "first desire to void" and 

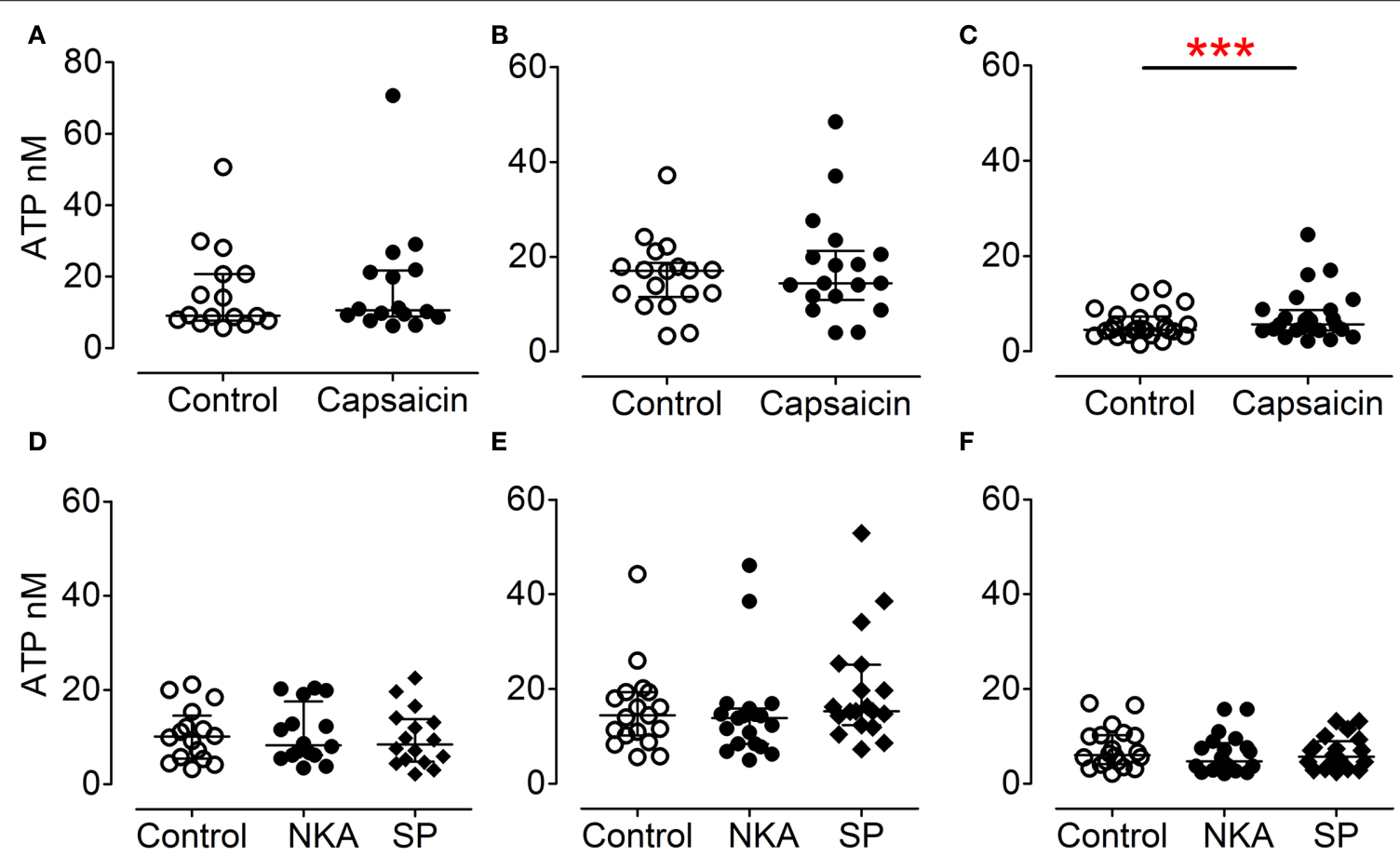

FIGURE 5 | Effect of capsaicin and tachykinins on ATP release from urothelial $(A, D)$, myofibroblast $(B, E)$, and muscle $(C, F)$ cultures. Capsaicin $(1 \mu \mathrm{M}$ in DMSO) had no effect on ATP release from urothelial [(A), $P=0.22$, $n=16$, Wilcoxon] or myofibroblast [(B), $P=0.31, n=18$, Wilcoxon] cultures, but was an effective stimulus in muscle cultures [(C), $P=0.0005, n=25$, Wilcoxon]. Neurokinin $A$ and substance $P$ (both $1 \mu \mathrm{M}$, in peptide solution) had no effect on urothelial [(D), $P=0.44, n=16$, Friedman's test], myofibroblast $[(\mathbf{E}), P=0.08, n=19$, Friedman's], or detrusor $[(\mathbf{F}), n=20]$ cultures. "maximal cystometric capacity" but not with the parameter of detrusor pressure (Cheng et al., 2010).

Acid was able to stimulate ATP release from only one cell type, the urothelial cells, perhaps via activation of acid-sensitive ion channels (ASIC; Kobayashi et al., 2009; Kullmann et al., 2009; Corrow et al., 2010). We have previously reported that acid is a stimulus for ATP release in rat and pig mucosal strips (Sadananda et al., 2009a,b). These porcine strips contained urothelial and myofibroblast cells (as well as other cell types) exposed to the acidic bath fluid, and we were unable to determine conclusively which cell type was responsible for the acid induced ATP release. In the current study, we have demonstrated that acid ( $\mathrm{pH}$ 6.4) was only able to stimulate ATP release from urothelial cells, and not from myofibroblast or muscle cells. This makes sense, since in vivo, the acidic stimulus in bladder would originate from the urine, which is in contact with the urothelial cells but not with the myofibroblasts or detrusor muscle cells.

Some anomalous results were obtained with the TRPV1 agonist, capsaicin. Capsaicin elicited ATP release in earlier studies with cultured rat urothelial cells (Birder et al., 2002), but it was ineffective in eliciting ATP release in our porcine urothelial or myofibroblast cultures. This may be due to species differences or due to a loss of TRPV1 receptor expression with culture. We have previously reported a 40 -fold increase in release of ATP in response to capsaicin stimulation in rat bladder mucosal strips (Sadananda et al., 2009b) although capsaicin was surprisingly ineffective in porcine bladder mucosal strips (Sadananda et al., 2009a). It is also notable that capsaicin had no effect in eliciting contractile responses in pig detrusor or mucosal strips (Sadananda et al., 2009a), although TRPV1 mRNA is expressed in both mucosa (urothelial cells and lamina propria) and detrusor layers in fresh pig bladder tissue (Kao et al., 2010). However, in our current study, capsaicin induced ATP release from porcine detrusor muscle cells, but not from urothelial or myofibroblast cells. This suggests that even if TRPV1 expression is maintained in culture, TRPV1 signaling pathways may be different in myofibroblasts and/or urothelial cells compared with detrusor muscle cells. Indeed, differences have been reported in TRPV1 functionality between urothelial and afferent-fiber TRPV1 (Birder et al., 2001; Avelino and Cruz, 2006). For example, unlike neuronal TRPV1, urothelial TRPV1 does not desensitize (Birder et al., 2001).

The tachykinins neurokinin A and substance $\mathrm{P}$ have long been postulated to have a role in bladder sensation and are thought to be important for processing information about bladder fullness, distension, and pain (Lecci and Maggi, 2001). In addition, the tachykinins have motor actions in the bladder (Templeman et al., 2003; Sellers et al., 2006) and NKA was able to contract porcine mucosal strips, as shown previously (Sadananda et al., 2008). However, neither neurokinin A nor substance $\mathrm{P}$ was able to stimulate ATP release from porcine bladder urothelial, myofibroblast, or muscle cell cultures. This result seems at variance with parallel studies from our group (Burcher et al., 2010), where NKA significantly increased ATP release from pig mucosal strips although the cell type involved was not identified. It is possible that one or 
more cell types could have changed phenotypically in culture, with downregulation of tachykinin receptors, making the cultured cells unresponsive to this stimulus.

In conclusion, we have isolated myofibroblast cells as a unique cell population, as evidenced by their differences from urothelial and detrusor muscle cells, with respect to morphology, immunostaining, and ATP release. All three types of cell culture released ATP in response to hypotonic media, demonstrating further the important role of ATP in mechanotransduction in normal bladder functioning. In addition, acid was able to stimulate ATP release from urothelial cells, the only cell type normally exposed to (acidic) urine. Finally, capsaicin stimulated ATP release from muscle cells, but the tachykinins, NKA, and SP, were unable to elicit ATP release from any of three bladder cell populations. Established cultures of myofibroblasts may facilitate further investigation of the physiological functions of this poorly studied but important cell layer.

\section{ACKNOWLEDGMENTS}

This study was supported by grants from the National Health and Medical Council of Australia and Pfizer OAB-LUTS Competitive Grants Program. We thank Li Wen for assistance with the immunocytochemical imaging and Donna Hamilton for facilitating provision of the pig bladders.

\section{REFERENCES}

Akino, H., Chapple, C. R., McKay, N., Cross, R. L., Murakami, S., Yokoyama, O., Chess-Williams, R., and Sellers, D. J. (2008). Spontaneous contractions of the pig urinary bladder: the effect of ATPsensitive potassium channels and the role of the mucosa. BJU Int. $102,1168-1174$.

Avelino, A., and Cruz, F. (2006). TRPV1 (vanilloid receptor) in the urinary tract: expression, function and clinical applications. Naunyn Schmiedebergs Arch. Pharmacol. 373, 287-299.

Birder, L., Kanai, A. J., de Groat, W. C., Kiss, S., Nealen, M. L., Burke, N. E., Dineley, K. E., Watkins, S., Reynolds, I. J., and Caterina, M. J. (2001). Vanilloid receptor expression suggests a sensory role for urinary bladder epithelial cells. Proc. Natl. Acad. Sci. U.S.A. 98, 13396-13401.

Birder, L. A. (2006). Urinary bladder urothelium: molecular sensors of chemical/thermal/mechanical stimuli. Vascul. Pharmacol. 45, 221-226.

Birder, L. A., Barrick, S. R., Roppolo, J. R., Kanai, A. J., de Groat, W. C., Kiss, S., and Buffington, C. A. (2003). Feline interstitial cystitis results in mechanical hypersensitivity and altered ATP release from bladder urothelium. Am. J. Physiol. Renal Physiol. 285, F423-F429.

Birder, L. A., Nakamura, Y., Kiss, S., Nealen, M. L., Barrick, S., Kanai, A. J., Wang, E., Ruiz, G., de Groat, W. C., Apodaca, G., Watkins, S., and Caterina, M. J. (2002). Altered urinary bladder function in mice lacking the vanilloid receptor TRPV1. Nat. Neurosci. 5, 856-860.

Burcher, E., Teahan, O., Shang, F., Sandow, S., and Sadananda, P. (2010). "Investigation of receptors and mediator release in the porcine bladder mucosa - a role for tachykinins and other endogenous agonists?" in Proceedings of Australasian Society of Clinical and Experimental Pharmacologists and Toxicologists (ASCEPT), Melbourne, 150. Available at: http://ascept.eproceedings .com.au/abstracts.html (Abstract).

Burcher, E., Zeng, X. P., Strigas, J., Shang, F., Millard, R. J., and Moore, K. H. (2000). Autoradiographic localization of tachykinin and calcitonin gene-related peptide receptors in adult urinary bladder. J. Urol. 163, 331-337.

Burnstock, G. (2007). Physiology and pathophysiology of purinergic neurotransmission. Physiol. Rev. 87, 659-797.

Charrua, A., Reguenga, C., Cordeiro, J. M., Correiade-Sá, P., Paule, C., Nagy, I., Cruz, F., and Avelino, A. (2009). Functional transient receptor potential vanilloid 1 is expressed in human urothelial cells. J. Urol. 182, 2944-2950.

Cheng, Y., Mansfield, K. J., Allan, W., Walsh, C. A., Burcher, E., and Moore, K. H. (2010). Does ATP released into cystometric bladder washings contribute to the signalling of urgency in women with bladder dysfunction? J. Urol. 183, 1082-1086.

Cockayne, D. A., Hamilton, S. G., Zhu, Q. M., Dunn, P. M., Zhong, Y., Novakovic, S., Malmberg, A. B., Cain, G., Berson, A., Kassotakis, L., Hedley, L., Lachnit, W. G., Burnstock, G., McMahon, S. B., and Ford, A. P. (2000). Urinary bladder hyporeflexia and reduced painrelated behaviour in P2X3-deficient mice. Nature 407, 1011-1015.

Corrow, K., Girard, B. M., and Vizzard, M. A. (2010). Expression and response of acid-sensing ion channels (ASICs) in urinary bladder to cyclophosphamide (CYP)-induced cystitis. Am. J. Physiol. Renal Physiol. 298, F1130-F1139.

Davidson, R. A., and McCloskey, K. D. (2005). Morphology and localization of interstitial cells in the guinea pig bladder: structural relationships with smooth muscle and neurons. J. Urol. 173, 1385-1390.

Drake, M. J., Fry, C. H., and Eyden, B. (2006). Structural characterization of myofibroblasts in the bladder. $B J U$ Int. 97, 29-32.

Eichner, R., Bonitz, P., and Sun, T.T. (1984). Classification of epidermal keratins according to their immunoreactivity, isoelectric point and mode of expression. J. Cell Biol. 98, 1388-1396.

Ferguson, D. R., Kennedy, I., and Burton, T. J. (1997). ATP is released from rabbit urinary bladder epithelial cells by hydrostatic pressure changes-a possible sensory mechanism? J. Physiol. 505, 503-511.

Fry, C. H., Sui, G.-P., Kanai, A. J., and $\mathrm{Wu}, \mathrm{C}$. (2007). The function of suburothelial myofibroblasts in the bladder. Neurourol. Urodyn. 26 914-919.

Gallanti, A., Prelle, A., Moggio, M., Ciscato, P., Checcarelli, N., Sciacco, M., Comini, A., and Scarlato, G. (1992). Desmin and vimentin as markers of regeneration in muscle diseases. Acta Neuropathol. 85, 88-92.

Gillespie, J. I., Markerink-van Ittersum, M., and De Vente, J. (2006). Endogenous nitric oxide/cGMP signalling in the guinea pig bladder: evidence for distinct populations of sub-urothelial interstitial cells. Cell Tissue Res. 325, 325-332.

Hashitani, H., and Brading, A. F. (2003). Electrical properties of detrusor smooth muscles from the pig and human urinary bladder. Br. J. Pharmacol. 140, 146-158.

Hernández, M., Knight, G. E., Wildman, S. S., and Burnstock, G. (2009). Role of ATP and related purines in inhibitory neurotransmission to the pig urinary bladder neck. $\mathrm{Br}$. J. Pharmacol. 157, 1463-1473.

Iwanaga, K., Murata, T., Hori, M., and Ozaki, H. (2010). Isolation and characterization of bovine intestinal subepithelial myofibroblasts. $J$. Pharmacol. Sci. 112, 98-104.
Johnston, L., Woolsey, S., Cunningham, R. M., O’Kane, H., Duggan, B., Keane, P., and McCloskey, K. D. (2010). Morphological expression of KIT positive interstitial cells of Cajal in human bladder. J. Urol. 184, 370-377.

Kao, F. C. L., Shang, F., Teahan, O., Liu, L., and Burcher, E. (2010). "Acid and acid-sensitive receptors in the porcine urinary bladder," in Proceedings of Australasian Society of Clinical and Experimental Pharmacologists and Toxicologists (ASCEPT), Melbourne, 156. Available at: http://ascept.eproceedings .com.au/abstracts.html (Abstract).

Kobayashi, H., Yoshiyama, M., Zakoji, H., Takeda, M., and Araki, I. (2009). Sex differences in the expression profile of acid-sensing ion channels in the mouse urinary bladder: a possible involvement in irritative bladder symptoms. BJU Int. 104, 1746-1751.

Kullmann, F. A., Shah, M. A., Birder, L. A., and de Groat, W. C. (2009). Functional TRP and ASIC-like channels in cultured urothelial cells from the rat. Am. J. Physiol. 296, F892-F901.

Kumar, V., Chapple, C. R., and ChessWilliams, R. (2004). Characteristics of ATP release from porcine and human normal bladder. J. Urol. 172, 744-747.

Kumar, V., Chapple, C. R., Rosario, D., Tophill, P. R., and ChessWilliams, R. (2010). In vitro release of adenosine triphosphate from the urothelium of human bladders with detrusor overactivity, both neurogenic and idiopathic. Eur. Urol. 57, 1087-1092.

Kumar, V., Chapple, C. R., Surprenant, A. M., and Chess-Williams, R. (2007). Enhanced adenosine triphosphate release from the urothelium of patients with painful bladder syndrome: a possible pathophysiological explanation. J. Urol. 178, 1533-1536. 
Lecci, A., and Maggi, C. A. (2001). Tachykinins as modulators of the micturition reflex in the central and peripheral nervous system. Regul. Pept. 101, 1-18.

Liu, F., Takahashi, N., and Yamaguchi, O. (2009). Expression of $\mathrm{P} 2 \mathrm{X} 3$ purinoceptors in suburothelial myofibroblasts of the normal human urinary bladder. Int. J. Urol. 16, 570-575.

McCloskey, K. D. (2010). Interstitial cells in the urinary bladder - localization and function. Neurourol. Urodyn. 29, 82-87.

Munoz, A., Gangitano, D. A., Smith, C. P., Boone, T. B., and Somogyi, G. T. (2010). Removal of urothelium affects bladder contractility and release of ATP but not NO in rat urinary bladder. BMC Urol. 10, 10.

Nair, D. G., Han, T. Y., Lourenssen, S., and Blennerhassett, M. G. (2011). Proliferation modulates intestinal smooth muscle phenotype in vitro and in colitis in vivo. Am. J. Physiol. 300, G903-G913.

Paulin, D., and Li, Z. (2004). Desmin: a major intermediate filament protein essential for the structural integrity and function of muscle. Exp. Cell Res. 301, 1-7.

Rasmussen, H., Rumessen, J. J., Hansen, A., Smedts, F., and Horn, T. (2009). Ultrastructure of Cajal-like interstitial cells in the human detrusor. Cell Tissue Res. 335, 517-527.

Roholl, P. J. M., Elbers, H. R. J., Prinsen, I., Claessens, J. A. J., and Van Unnik, J. A. M. (1990). Distribution of actin isoforms in sarcomas: an immunohistochemical study. Hum. Pathol. 21, 1269-1274.
Sadananda, P., Chess-Williams, R. and Burcher, E. (2008). Contractile properties of the pig bladder mucosa in response to neurokinin A: a role for myofibroblasts? Br. J. Pharmacol. 153, 1465-1473.

Sadananda, P., Mansfield, K. J., and Burcher, E. (2009a). Acid, but not capsaicin, is an effective stimulus for ATP release in the porcine bladder mucosa. Neurourol. Urodyn. 28, 866-867.

Sadananda, P., Shang, F., Liu, L., Mansfield, K. J., and Burcher, E. (2009b). Release of ATP from rat urinary bladder mucosa: role of acid, vanilloids and stretch. Br. J. Pharmacol. 158,1655-1662.

Sandow, S. L., Sadananda, P., and Burcher, E. (2010). Innervated myofibroblasts in the urinary bladder? Functional and ultrastructural evidence. Neurourol. Urodyn. 29, 901-902.

Sandow, S. L., Tare, M., Coleman, H. A., Hill, C. E., and Parkington, $\mathrm{H}$. C. (2002). Involvement of myoendothelial gap junctions in the actions of endothelium-derived hyperpolarizing factor. Circ. Res. 90, 1108-1113.

Sellers, D. J., Chapple, C. R., Hay, D. P. W., and Chess-Williams, R. (2006). Depressed contractile responses to neurokinin A in idiopathic but not neurogenic overactive human detrusor muscle. Eur. Urol. 49, 510-518.

Smet, P. J., Moore, K. H., and Jonavicius, J. (1997). Distribution and colocalization of calcitonin gene-related peptide, tachykinins, and vasoactive intestinal peptide in normal and idiopathic unstable human urinary bladder. Lab. Invest. 77, 37-49.
Southgate, J., Harnden, P., and Trejdosiewicz, L. K. (1999). Cytokeratin expression patterns in normal and malignant urothelium: a review of the biological and diagnostic implications. Histol. Histopathol. 14, 657-664.

Sui, G.-P., Wu, C., and Fry, C. H. (2006) Characterization of the purinergic receptor subtype on guinea-pig suburothelial myofibroblasts. BJU Int. 97, 1327-1331.

Sun, T.-T., Eichner, R., Schermer, A. Cooper, D., Nelson, W. G., and Weiss, R. A. (1984). "Classification, expression and possible mechanisms of evolution of mammalian epithelial keratins: a unifying model," in Cancer Cells 1 The Transformed Phenotype, eds A. Levine, W. Topp, G. Vande Woude, and J. D. Watson (New York: Cold Spring Harbor Laboratory), 169-176.

Sun, Y., and Chai, T. C. (2002). Effects of dimethyl sulphoxide and heparin on stretch-activated ATP release by bladder urothelial cells from patients with interstitial cystitis. BJU Int. 90, 381-385.

Sun, Y., Keay, S., de Deyne, P. G., and Chai, T. C. (2001). Augmented stretch activated adenosine triphosphate release from bladder uroepithelial cells in patients with interstitial cystitis. J. Urol. 166, 1951-1956.

Templeman, L., Sellers, D. J., Chapple, C. R., and Chess-Williams, R. (2003). Investigation of neurokinin2 and -3 receptors in the human and pig bladder. BJU Int. 92, 787-792.

Trifillis, A. L., Cui, X., Jacobs, S., and Warren, J. W. (1995). Culture of bladder epithelium from cystoscopic biopsies of patients with interstitial cystitis. J. Urol. 153, 243-248.

Wood, D. N., Brown, R. A., and Fry, C. H. (2004). Characterization of the control of intracellular $[\mathrm{Ca} 2+]$ and the contractile phenotype of cultured human detrusor smooth muscle cells. J. Urol. 172, 753-757.

Wu, C., Sui, G. P., and Fry, C. H. (2004). Purinergic regulation of guinea pig suburothelial myofibroblasts. $J$. Physiol. (Lond.) 559, 231-234.

Conflict of Interest Statement: The authors declare that the research was conducted in the absence of any commercial or financial relationships that could be construed as a potential conflict of interest.

Received: 13 March 2011; accepted: 23 May 2011; published online: 07 June 2011.

Citation: Cheng Y, Mansfield KJ, Sandow SL, Sadananda P, Burcher E and Moore KH (2011) Porcine bladder urothelial, myofibroblast, and detrusor muscle cells: characterization and ATP release. Front. Pharmacol. 2:27. doi: 10.3389/fphar.2011.00027

This article was submitted to Frontiers in Cardiovascular and Smooth Muscle Pharmacology, a specialty of Frontiers in Pharmacology. Copyright (C) 2011 Cheng, Mansfield, Sandow, Sadananda, Burcher and Moore. This is an open-access article subject to a non-exclusive license between the authors and Frontiers Media SA, which permits use, distribution and reproduction in other forums, provided the original authors and source are credited and other Frontiers conditions are complied with. 